\title{
The cost burden of Crohn's disease and ulcerative colitis depending on biologic treatment status - a Danish register-based study
}

Sarah Alulis $^{1 *}$ (D, Kasper Vadstrup ${ }^{1}$, Jens Olsen ${ }^{2}$, Tine Rikke Jørgensen ${ }^{3}$, Niels Qvist ${ }^{4}$, Pia Munkholm ${ }^{5}$ and Andras Borsi ${ }^{6}$

\begin{abstract}
Background: Patients diagnosed with inflammatory bowel disease may be treated with biologics, depending on several medical and non-medical factors. This study investigated healthcare costs and production values of patients treated with biologics.

Methods: This national register study included patients diagnosed with Crohn's disease (CD) and ulcerative colitis (UC) between 2003 and 2015, identified in the Danish National Patient Register (DNPR). Average annual healthcare costs and production values were compared for patients receiving biologic treatment or not, and for patients initiating biologic treatment within a year after diagnosis or at a later stage. Cost estimates and production values were based on charges, fees and average gross wages.

Results: Twenty-six point one percent CD patients and ten point seven percent of UC patients were treated with biologics at some point in the study period. Of these, 46.4 and $45.5 \%$ of patients initiated biologic treatment within the first year after diagnosis. CD and UC patients treated with biologics had higher average annual healthcare costs after diagnosis compared to patients not treated with biologics. CD patients receiving biologics early had lower production values both ten years before and eight years after treatment initiation, compared to patients receiving treatment later. UC patients receiving biologics early had lower average annual production values the first year after treatment initiation compared to UC patients receiving treatment later.
\end{abstract}

Conclusions: $C D$ and UC patients receiving biologic treatment had higher average annual healthcare costs and lower average annual production values, compared to patients not receiving biologic treatment. The main healthcare costs drivers were outpatient visit costs and admission costs.

Keywords: Epidemiology, National register data, Health economy, Societal burden, IBD, CD, UC

\section{Background}

Inflammatory bowel diseases (IBD), Crohn's disease (CD) and ulcerative colitis (UC), are chronic diseases that affect people of all ages; but the majority of newly diagnosed patients are adolescents and those in early

\footnotetext{
* Correspondence: salulis@its.jnj.com

${ }^{1}$ Janssen-Cilag, Bregnerødvej 133, 3460 Birkerød, Denmark

Full list of author information is available at the end of the article
}

adulthood [1]. The cause of IBD remains unknown, however elements such as environment, genetics, and immunoregulatory factors are all thought to be associated [2]. Disease severity is classified as being mild, moderate or severe and the treatment patients may receive depends on this. Typically, patients with moderate to severe disease will receive biological treatment, depending on several medical and non-medical factors. As each

(C) The Author(s). 2021 Open Access This article is licensed under a Creative Commons Attribution 4.0 International License, which permits use, sharing, adaptation, distribution and reproduction in any medium or format, as long as you give appropriate credit to the original author(s) and the source, provide a link to the Creative Commons licence, and indicate if changes were made. The images or other third party material in this article are included in the article's Creative Commons licence, unless indicated otherwise in a credit line to the material. If material is not included in the article's Creative Commons licence and your intended use is not permitted by statutory regulation or exceeds the permitted use, you will need to obtain permission directly from the copyright holder. To view a copy of this licence, visit http://creativecommons.org/licenses/by/4.0/ The Creative Commons Public Domain Dedication waiver (http://creativecommons.org/publicdomain/zero/1.0/) applies to the data made available in this article, unless otherwise stated in a credit line to the data. 
patient's IBD presents differently, treatment needs to be tailored to their specific situation [2].

Due to the chronic nature of IBD and its symptoms, quality of life is greatly impacted. An online survey across 25 national IBD associations found that $56 \%$ of patients with $\mathrm{CD}$ felt that their disease affected their career and $17 \%$ believed that $\mathrm{CD}$ caused their relationship to end [3]. In addition to the personal and emotional effects of IBD, a patient's ability to work is often impacted. Studies show that having UC is associated with higher indirect costs related to loss of productivity [4], including the areas of sick leave, shorter working days, and early retirement. A previous study conducted in the United Kingdom found that the majority of UC patients experienced professional challenges related to their choice in work and the amount of time they could spend working [5]. Therefore, the aim of the present study was to explore the average annual healthcare costs and production values of patients ten years before their IBD diagnosis and in the eight-year period after initiating biologic treatment in Denmark.

\section{Methods}

\section{Study population and study design}

This retrospective population-based study explored the costs of having an IBD diagnosis, stratified on CD, UC, and biologic treatment status. Data on all Danish residents was retrieved from the Danish Civil Registration System (CRS) [6], that includes all citizens and residents with a civil personal registration number, enabling an identity-secure linkage of information between the national registries. Patient specific data was collected from the National Health Service Register (NHSR) [6-8], the Danish National Patient Registry (NPR) [7, 9, 10], the Cause of Death Register [7] and the Danish Longitudinal Database on Employment (DREAM) [11].

The DREAM database, owned by the Danish Ministry of Employment, includes information on weekly labour market transfer payments for all Danish citizens, since 1991 [11]. Only individuals receiving a labour market related social benefit payment are included in the database in the corresponding year. Hence, individuals that were employed, full-time the entire year are not included in the database. Yearly employment rates were estimated using the DREAM database.

The study population included all adults above 18 years of age diagnosed with CD or UC between 2003 and 2015 with the following selection criteria: (1) Individuals with at least two hospital contacts (admissions, outpatient or emergency room visits) collected from the NPR, with a primary or secondary diagnosis of CD or UC using the International Classification of Diseases 10th edition (ICD-10) code $\mathrm{K} 50$ and $\mathrm{K} 51$ and with at least one of the registrations defined as the primary diagnosis; (2) patient with no hospital contacts related to CD or UC during 1994-2002 (wash-out period). Further, index date was defined as the first hospital contact including either admission, outpatient or emergency room visit with diagnosis of $\mathrm{CD}$ or UC. Patients diagnosed with UC followed by a CD diagnosis were considered as diagnosed with $\mathrm{CD}$. The study design, other analyses and results have previously been published [12-14].

The patients diagnosed with CD and UC were categorized into two groups: (1) Those who received $\mathrm{CD}$ or $\mathrm{UC}$ related biologic treatment with at least one hospital contact with a registered biologics treatment code in the period 2003-2016, and (2) those who did not receive $\mathrm{CD}$ or UC related biologic treatment in the period 2003-2016. Four biologic treatments were available during the study period: infliximab, adalimumab, vedolizumab and golimumab and were identified in the NPR using their treatment code. Those receiving biologic treatment were further divided into two sub-groups: 1a) Patients that initiated biologic treatment within the first year from their $C D$ or UC diagnosis, and $1 b$ ) patients that initiated biologic treatment more than a year after diagnosis.

Patients were censored (excluded) at death and at end of follow-up (2016). In the year of death or the end of follow-up, the individual was included with a weight corresponding to the fraction of the year data were available for them.

\section{Costs and production value}

Healthcare costs and production values were extracted from the NHSR, the NPR and the DREAM database. All contacts with the primary healthcare and hospital sector are collected in the NHSR and the NPR, respectively. The primary healthcare sector includes general practitioners, private practicing medical specialists and other private practicing healthcare professionals such as chiropractors and psychologists. The hospital sector includes admissions, outpatient and emergency room visits. The gross fee paid for each contact with a healthcare professional came from the NHSR, and outpatient (DAGS) and Diagnosis Related Group (DRG) charges for each contact were extracted from the NPR. Total healthcare costs included primary sector contacts, outpatient contacts, hospital admissions and gross fees (primary care sector), and charges (outpatient contacts and admissions) were applied as unit cost estimates.

In Denmark, the prescription of and treatment with biologics occurs solely within the hospital sector (i.e., $100 \%$ publicly financed hospital drugs). IBD patients are not treated in private hospitals, as private insurance does not cover the funding of biologics. Treatment with intravenous therapies, such as infliximab and vedolizumab, always takes place in a hospital, usually during an 
outpatient visit. Treatment with subcutaneous treatments, such as adalimumab and golimumab, may be given in the hospital or the patient may administer it at home. If administrated at home, the patient needs to pick up the medicine at least every three months from the hospital, in which it will be registered as an outpatient contact. The drug costs are either included in the cost of the admission or in the outpatient contacts (i.e. the DRG/DAGS charge). All biologics included in this analysis are included in the national treatment guidelines, therefore implying that compassionate use programs are not relevant and/or do not exist for this patient population.

The average annual production value was estimated using weekly employment data from the DREAM database on employment. Using this database, the annual employment rate for all patients included was estimated as the percentage of the year employed and unemployed, respectively. Production values were then estimated by multiplying the annual employment rate with a gender specific gross average annual wage, adjusted for the number of effective weekly working hours $[15,16]$. For estimation of production value, only individuals between the age of 18 and 65 each year were included, as they are considered to constitute the work force.

Fees in the NHSR and DAGS and DRG charges in the NPR were inflated using the relevant combined price and wage index for healthcare services, estimated by the Danish Regions [17]. All costs and production values are presented in the 2016 price level. All costs are reported in Euros with the exchange rate of $€ 1=$ DKK 7.5.

\section{Statistical analyses}

Two main analyses were conducted. The first analysis investigated the average annual costs and production value of $\mathrm{CD}$ and $\mathrm{UC}$ patients, before and after diagnosis. Patients receiving biologic treatment after diagnosis were compared to patients that did not receive biologic treatment after diagnosis. The second analysis consisted of the average annual costs and production value in the period after biologic treatment initiation for the subgroups of $\mathrm{CD}$ and UC patients on biologic treatment. Patients that initiated biologic treatment within the first year after diagnosis (i.e. early treatment initiation) were compared to those patients that initiated biologic treatment more than a year after diagnosis (i.e. late treatment initiation).

For the first analysis, average annual costs and production value per individual were calculated in the ten-year period prior to the $\mathrm{CD}$ and UC incidence date, and the eight-year period after the incidence date. As the two patient groups may not be comparable in terms of age and gender distribution, a linear regression model was conducted and adjusted for age and gender. For the second analysis, average annual costs and production value per individual were calculated in the year prior to the date of biologic treatment initiation and then up to eight years after the biologic treatment initiation date. This was done for the two sub-groups of patients receiving biologic treatment within the first year of diagnosis, and for patients receiving biologic treatment more than one year after diagnosis.

All statistical analyses were conducted in SAS version 9.4 (SAS Institute Inc, Cary, NC, USA) on Statistics Denmark's research computers via a remote server.

\section{Results}

Between 2003 and 2015, a total of 9,019 CD and 20,913 UC patients were identified in the NPR. Of these, 2,351 CD (26.1\%) and 2,248 UC patients (10.7\%) received diagnosis related biologic treatment at some point during the study period, Table 1 . Among the $\mathrm{CD}$ diagnosed patients who were treated with biologics, 1,091 (46.4\%) initiated treatment within the first year after diagnosis, whereas 1,260 (53.6\%) initiated treatment more than a year after diagnosis. For the UC patients treated with biologics, 1,022 (45.5\%) initiated treatment within the first year after diagnosis and 1,226 (54.5\%) patients began treatment later.

\section{Treatment of biologics vs. not treated with biologics}

Overall, CD and UC patients who received biologic treatment had higher average annual healthcare costs after diagnosis compared to patients who did not receive biologic treatment, Fig. 1. The first and second year after diagnosis, the average total healthcare costs among $\mathrm{CD}$ patients receiving biologic treatment were $€ 5,828$ and $€ 8,013$ higher compared to patients not receiving biologic treatment. Among UC patients receiving biologic treatment, the average total costs in the first and second year after diagnosis exceeded those of the UC patients not receiving biologic treatment with $€ 6,948$ and $€ 6,066$ respectively. Eight years after diagnosis, the differences decreased to $€ 6,618$ for $C D$ and $€ 2,412$ for UC patients.

The main healthcare cost drivers were outpatient visits and admission costs, which were overall higher among patients receiving biologics treatment, Fig. 1. Admission costs were higher in the first four years after diagnosis for UC patients who were treated with biologics compared to patients not treated with biologics. Among $C D$ patients, admission costs were markedly higher the third, fourth and fifth year after diagnosis. The years prior to diagnosis, $\mathrm{CD}$ and UC patients not treated with biologics tended to have slightly higher admission costs.

Regarding primary sector costs, these were similar for the two patient groups. However, during the entire study period, patients that did not receive biologic treatment incurred higher costs compared to the patients that did, 
Table 1 Number of persons initiating biologic treatment and population size by year, CD and UC patients

\begin{tabular}{|c|c|c|c|c|c|c|c|c|c|c|c|c|c|c|c|}
\hline Year - & 2003 & 2004 & 2005 & 2006 & 2007 & 2008 & 2009 & 2010 & 2011 & 2012 & 2013 & 2014 & 2015 & 2016 & Total $^{\mathrm{a}}$ \\
\hline $\begin{array}{l}\text { CD patients initiating } \\
\text { biologic treatment }\end{array}$ & 0 & 5 & 20 & 67 & 166 & 168 & 201 & 257 & 236 & 252 & 243 & 274 & 280 & 182 & 2,351 \\
\hline $\begin{array}{l}\text { Incident CD population, } \\
\text { cumulated }\end{array}$ & 695 & 1,418 & 2,140 & 2,809 & 3,493 & 4,197 & 4,876 & 5,670 & 6,472 & 7,213 & 7,878 & 8,534 & 9,019 & & 9,019 \\
\hline $\begin{array}{l}\% \text { of incident } C D \\
\text { population initiating } \\
\text { biologics }\end{array}$ & $0.0 \%$ & $0.4 \%$ & $0.9 \%$ & $2.4 \%$ & $4.8 \%$ & $4.0 \%$ & $4.1 \%$ & $4.5 \%$ & $3.6 \%$ & $3.5 \%$ & $3.1 \%$ & $3.2 \%$ & $3.1 \%$ & & $26.1 \%$ \\
\hline $\begin{array}{l}\text { UC patients initiating } \\
\text { biologic treatment }\end{array}$ & 0 & 1 & 4 & 36 & 99 & 109 & 164 & 192 & 246 & 248 & 275 & 343 & 322 & 209 & 2,248 \\
\hline $\begin{array}{l}\text { Incident UC population, } \\
\text { cumulated }\end{array}$ & 1,610 & 3,286 & 4,938 & 6,513 & 8,063 & 9,736 & 11,604 & 13,432 & 15,399 & 17,011 & 18,503 & 19,858 & 20,913 & & 20,913 \\
\hline $\begin{array}{l}\% \text { of incident UC } \\
\text { population initiating } \\
\text { biologics }\end{array}$ & $0.0 \%$ & $0.0 \%$ & $0.1 \%$ & $0.6 \%$ & $1.2 \%$ & $1.1 \%$ & $1.4 \%$ & $1.4 \%$ & $1.6 \%$ & $1.5 \%$ & $1.5 \%$ & $1.7 \%$ & $1.5 \%$ & & $10.7 \%$ \\
\hline
\end{tabular}

The population of $\mathrm{CD} / \mathrm{UC}$ patients initiating biologic treatment each year include all patients derived from the incident population receiving treatment for the first time the year initiated biologic treatment

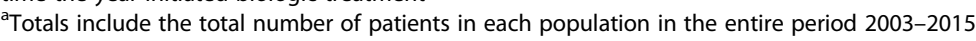

Fig. 1. The average annual production value per individual showed patients receiving biologic treatment had lower production value after their diagnosis, compared to patients that did not receive biologic treatment, Fig. 2.

The regression analyses adjusted for age and gender illustrated that after diagnosis, costs from outpatient visits and admissions were significantly lower among patients not receiving biologic treatment compared to patients receiving biologic treatment, Table 2. Patients not receiving treatment with biologics had a significantly higher production value after diagnosis compared to patients on biologic treatment. The primary sector costs, adjusted for age and gender, were higher some years before diagnosis, compared to patients treated with biologics, Table 2. There was however no statistically significant difference in primary sector costs between the patient groups after disease diagnosis.

Overall, the difference in healthcare costs the first and second year after diagnosis, when only considering the statistically significant results, were $€ 6,711$ and $€ 15,542$ for CD patients and $€ 7,822$ and $€ 6,821$ for UC patients. This is higher than what was shown in the unadjusted comparison.

\section{Timing of biologic treatment}

In general, the healthcare costs associated with early and late biologic treatment initiation were not very different.

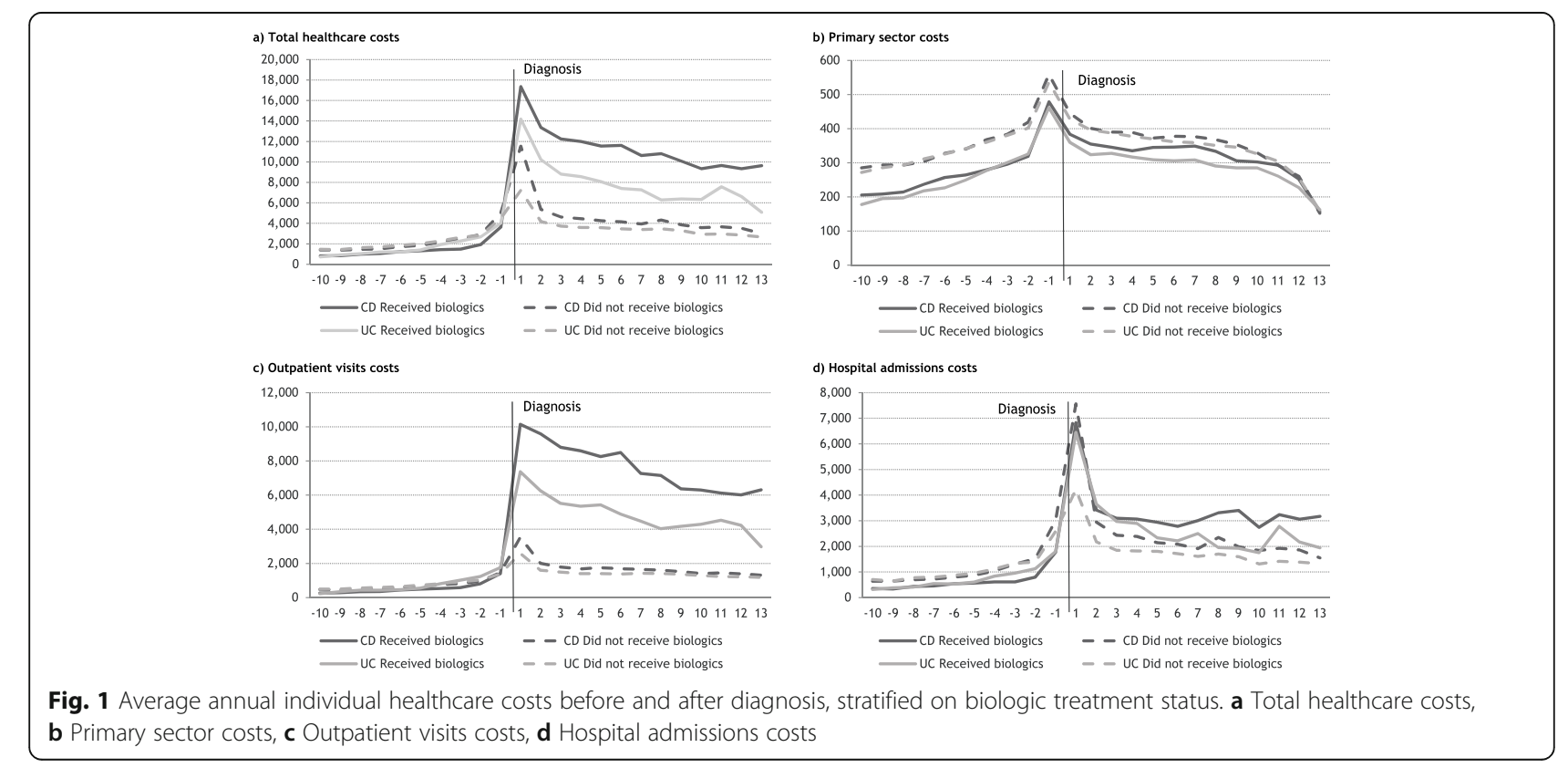




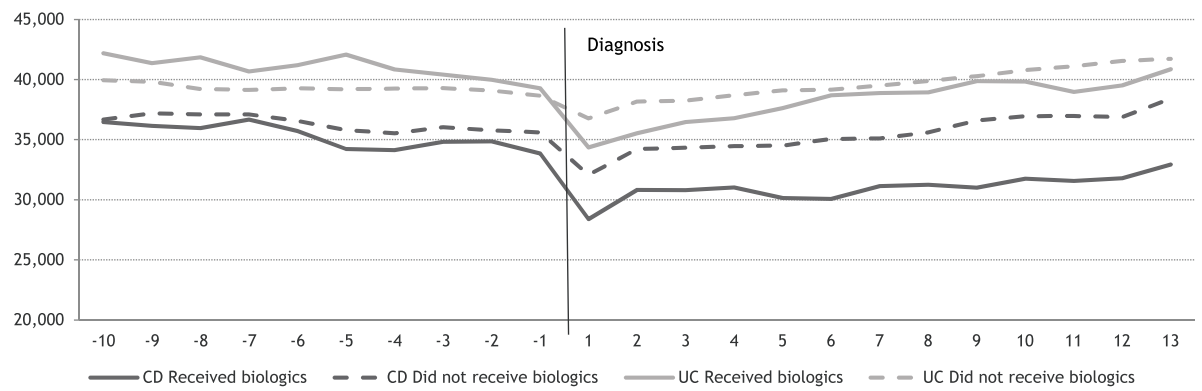

Fig. 2 Average annual individual production value before and after diagnosis, stratified on biologic treatment status

CD patients initiating biologic treatment earlier had on average $€ 1,309$ higher total healthcare costs the first year after treatment initiation, compared with $\mathrm{CD}$ patients initiating biologic treatment later, Fig. 3.

UC patients who initiated biologic treatment later had $€ 1,692$ lower total average healthcare costs (age and gender adjusted) during the first year after treatment initiation, compared to those with early initiation, Table 3 .
There were no significant differences in healthcare costs in the first year after treatment initiation among CD patients when adjusting for age and gender differences.

Overall, patients initiating biologics early had higher primary sector costs and admission costs before treatment initiation compared to patients initiating biologics later. Outpatient visit costs differed significantly among $\mathrm{CD}$ patients in the second, third and fourth year after

Table 2 Adjusted differences (receiving biologics or not) of individual annual healthcare costs and production value (Euros, 2016 prices)

\begin{tabular}{|c|c|c|c|c|c|c|c|c|}
\hline \multirow{2}{*}{$\begin{array}{l}\text { Years } \\
\text { from } \\
\text { diagnosis }\end{array}$} & \multicolumn{2}{|c|}{ Outpatient visits } & \multicolumn{2}{|c|}{ Hospital admissions } & \multicolumn{2}{|c|}{ Primary sector } & \multicolumn{2}{|c|}{ Production value } \\
\hline & $\overline{C D}$ & UC & $\overline{C D}$ & UC & $\overline{C D}$ & UC & $\overline{C D}$ & UC \\
\hline-10 & 111 & $145^{*}$ & 96 & 249 & 12 & $33^{*}$ & 345 & -1380 \\
\hline-9 & 64 & 71 & 118 & 88 & 23 & $28^{*}$ & 740 & -1142 \\
\hline-8 & 22 & 9 & 49 & 142 & 21 & $37^{*}$ & 214 & $-1989^{*}$ \\
\hline-7 & 32 & 43 & 26 & -14 & 8 & $31^{*}$ & -390 & -655 \\
\hline-6 & 17 & 34 & 69 & 89 & 15 & $33^{*}$ & 0 & -890 \\
\hline-5 & 15 & 28 & 23 & 42 & 14 & $24^{*}$ & 488 & -1426 \\
\hline-4 & 72 & $-150^{*}$ & 86 & 2 & 26 & 16 & 473 & -149 \\
\hline-3 & 71 & $-278^{*}$ & $285^{*}$ & 17 & $28^{*}$ & 13 & 538 & 48 \\
\hline-2 & -53 & $-395^{*}$ & 193 & -170 & $39^{*}$ & 9 & 547 & 76 \\
\hline-1 & -164 & $-619^{*}$ & $457^{*}$ & 70 & $29^{*}$ & 13 & $1419^{*}$ & 393 \\
\hline 1 & $-6711^{*}$ & $-4914^{*}$ & -367 & $-2908^{*}$ & 6 & -7 & $3611^{*}$ & $3460^{*}$ \\
\hline 2 & $-7698^{*}$ & $-4859^{*}$ & $-1133^{*}$ & $-1962^{*}$ & -7 & 3 & $3451^{*}$ & $3810^{*}$ \\
\hline 3 & $-7127^{*}$ & $-4203^{*}$ & $-1259^{*}$ & $-1618^{*}$ & -4 & -8 & $3609^{*}$ & $2887^{*}$ \\
\hline 4 & $-7060^{*}$ & $-4089^{*}$ & $-1293^{*}$ & $-1507^{*}$ & 11 & -2 & $3713^{*}$ & $3077^{*}$ \\
\hline 5 & $-6662^{*}$ & $-4171^{*}$ & $-1289^{*}$ & $-1041^{*}$ & -16 & 2 & $4592^{*}$ & $2802^{*}$ \\
\hline 6 & $-6883^{*}$ & $-3637^{*}$ & $-1167^{*}$ & $-962^{*}$ & -8 & -1 & $5184^{*}$ & $1831^{*}$ \\
\hline 7 & $-5751^{*}$ & $-3171^{*}$ & $-1462^{*}$ & $-1249^{*}$ & -9 & -4 & $4483^{*}$ & $2322^{*}$ \\
\hline 8 & $-5689^{*}$ & $-2768^{*}$ & $-1440^{*}$ & $-621^{*}$ & 3 & 8 & $5127^{*}$ & $2858^{*}$ \\
\hline 9 & $-4981^{*}$ & $-2959^{*}$ & $-1651^{*}$ & $-717^{*}$ & 14 & 13 & $6618^{*}$ & $2358^{*}$ \\
\hline 10 & $-4976^{*}$ & $-3077^{*}$ & $-1169^{*}$ & $-695^{*}$ & -6 & -2 & $6491^{*}$ & $2835^{*}$ \\
\hline 11 & $-4806^{*}$ & $-3347^{*}$ & $-1807^{*}$ & $-1629^{*}$ & -28 & 4 & $6412^{*}$ & $3735^{*}$ \\
\hline 12 & $-4721^{*}$ & $-3086^{*}$ & $-1730^{*}$ & $-1161^{*}$ & -20 & -2 & $6366^{*}$ & 3443 \\
\hline 13 & $-5183^{*}$ & $-1848^{*}$ & $-2015^{*}$ & -832 & -30 & -28 & $7050^{*}$ & 2425 \\
\hline
\end{tabular}


treatment initiation. UC patients initiating treatment later had significantly lower admission costs in the first and second year after treatment initiation compared to patients initiating treatment early.

The average annual production values among CD patients treated with biologics within the first year, were lower both before and after biologic treatment initiation compared to patients who received biologic treatment later, Fig. 4. UC patients who received biologic treatment within the first year after diagnosis had a lower average annual production value the first year after treatment initiation compared to patients that received biologic treatment more than a year after diagnosis. Adjusting for age and gender, the difference in production value for UC patients was significant the first year after treatment initiation with an estimated higher production value of $€ 3,459$ compared to patients initiating treatment later. CD patients initiating treatment after one year had production values exceeding $€ 2,963$ - $€ 5,141$ in the first, fourth, fifth and sixth year after treatment initiation compared to earlier treated patients, Table 3.

\section{Discussion}

The general level and development of the average annual healthcare costs and production value of CD and UC patients before and after their diagnosis has previously been described in this population [12, 13]. Therefore, the current study compared the differences in healthcare costs and production value of $\mathrm{CD}$ and UC patients depending on if they received biologic treatment or not. More than a quarter of the CD study population received biologic treatment at some point in the period
2003-2016 after their diagnosis and more than $10 \%$ received biologic treatment after a UC diagnosis.

This study showed that CD and UC patients that received biologic treatment had higher average annual healthcare costs and lower average annual production values compared to patients that did not receive biologic treatment. Despite biologics being used more and more [14], this study implies that patients treated with a biologic still constitute a more severely affected patient population compared to those patients that did not initiate biologic treatment. However, registry data does not include disease severity information for IBD-patients, therefore this study was not able to control for it. Our findings that receiving treatment with biologics leads to higher overall healthcare costs in IBD patients are supported by other German and Canadian real world evidence studies $[18,19]$.

This study also zoomed in on the differences in costs and production value between patients initiating biologic treatment within the first year after diagnosis, and patients initiating biologic treatment more than one year after diagnosis. The differences observed between receiving early and late treatment appeared marginal and nonsystematic. However, after adjusting for age and gender, some of the results were significant and suggested that patients treated later had higher outpatient costs and production value, and lower admission costs the first years after treatment initiation, compared with earlier treated patients.

We need to also acknowledge that a subgroup of our cohort may have initiated biologic treatment very late after receiving an IBD diagnosis. Therefore, these patients may have a different disease course or severity and
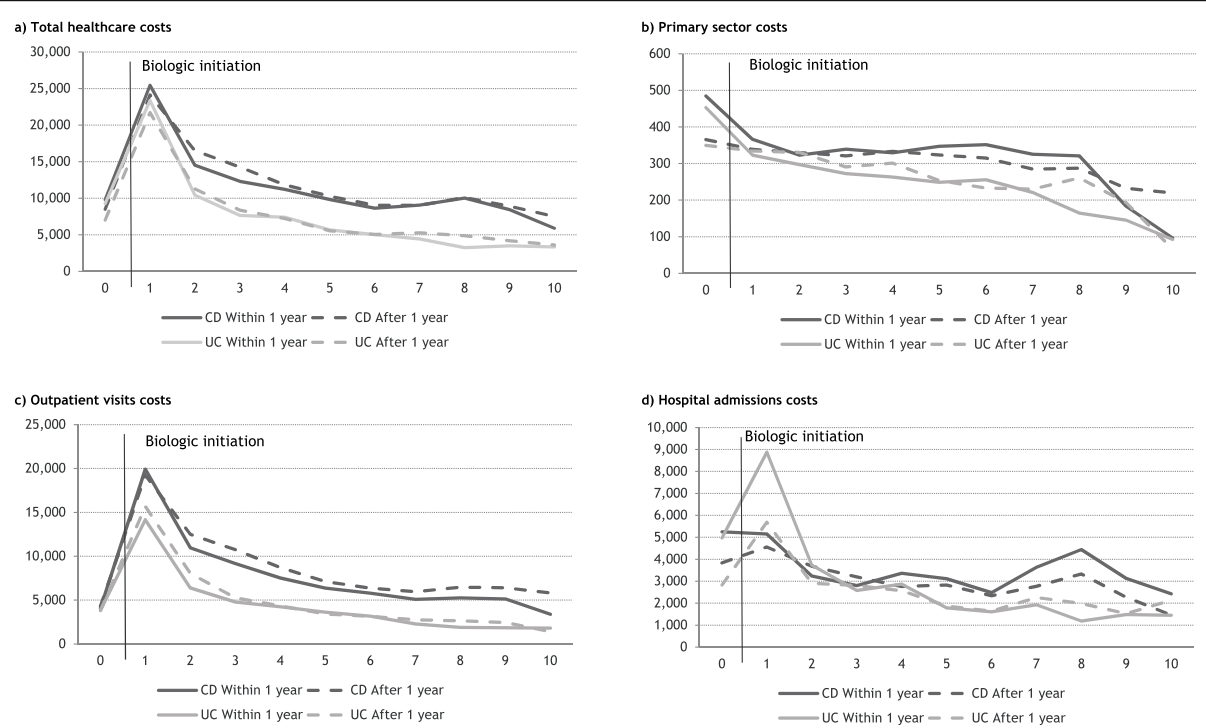

Fig. 3 Average annual individual healthcare costs after biologic initiation, stratified on timing of treatment initiation related to diagnosis. a Total healthcare costs, b Primary sector costs, c Outpatient visits costs, d Hospital admissions costs 
Table 3 Adjusted difference, individual annual healthcare costs and production value (patients initiating biologics within and after 1 year) (Euros, 2016 prices)

\begin{tabular}{|c|c|c|c|c|c|c|c|c|}
\hline \multirow{2}{*}{$\begin{array}{l}\text { Years from } \\
\text { biologic initiation }\end{array}$} & \multicolumn{2}{|c|}{ Outpatient visits } & \multicolumn{2}{|c|}{ Hospital admissions } & \multicolumn{2}{|c|}{ Primary sector } & \multicolumn{2}{|c|}{ Production value } \\
\hline & $C D$ & UC & $C D$ & UC & $C D$ & UC & $C D$ & UC \\
\hline 0 & 232 & -75 & $-1462^{*}$ & $-2200^{*}$ & $-122^{*}$ & $-114^{*}$ & 1938 & -169 \\
\hline 1 & -656 & $1497^{*}$ & -661 & $-3189^{*}$ & -30 & -1 & $2963^{*}$ & $3459^{*}$ \\
\hline 2 & $1563^{*}$ & $1583^{*}$ & 421 & $-872^{*}$ & 6 & 18 & 1314 & 1174 \\
\hline 3 & $1592^{*}$ & 434 & 385 & 237 & -19 & 7 & 2314 & 547 \\
\hline 4 & $1193^{*}$ & 69 & -596 & -324 & 3 & 27 & $2998^{*}$ & 810 \\
\hline 5 & 744 & -253 & -281 & 94 & -22 & 0 & $3941^{*}$ & 441 \\
\hline 6 & 569 & -7 & -133 & 22 & -34 & -29 & $5141^{*}$ & -256 \\
\hline 7 & 893 & 404 & -894 & 429 & -39 & -3 & 2605 & -129 \\
\hline 8 & 1204 & 635 & -1121 & 887 & -31 & $88^{*}$ & 4313 & -1880 \\
\hline 9 & 1244 & 429 & -795 & -133 & 48 & 33 & 3329 & 172 \\
\hline 10 & $2430^{*}$ & -505 & $-1221^{*}$ & 649 & $135^{*}$ & -34 & 4626 & 7436 \\
\hline
\end{tabular}

we cannot exclude that their healthcare cost may be lower, due to a shorter treatment period with more efficacious treatments. This study used a washout period of 10 years prior to inclusion, and we cannot exclude, that some patients diagnosed prior to the wash-out period might have been included. The number of patients that may have been included is considered to be very low due to clinical practice for IBD-patients in Denmark which includes a close follow-up, irrespective of disease activity. In a previous study using the same cohort, we have shown that biologic treatment does not change the cumulative surgical rate significantly in IBD-patients, and this may to some extent explain the increased costs in patients treated with biologics [20].

A previous study on the costs of $C D$ and $U C$ revealed higher healthcare costs after diagnosis compared to an age and gender matched control group free of IBD. Healthcare costs were especially high in the first years after diagnosis [12]. This trend is most likely explained by the difference in healthcare costs in the first year of patients initiating biologic treatment early and patients initiating treatment later (i.e. patients initiating biologic treatment later are beyond the "expensive" first year).
This study demonstrated that costs remained higher for patients treated with biologics more than a decade after diagnosis and that annual production values of patients receiving biologics were also lower a decade after diagnosis.

An important strength of this study is that selection bias and information bias is limited as the registries include all Danish residents, all data is prospectively collected, and the data quality is generally considered to be high. In addition, it is possible to follow patients for a potentially long period. Another strength is the broad perspective taken which includes both costs of outpatient visits and admissions, and primary healthcare sector costs and production values.

A limitation of the present study could be misclassification as we have had to rely on the accuracy of the ICD-10 coding in the NPR to identify CD and UC patients. In general, the reliability and validity of the diagnosis registration in the NPR are assessed to be adequate [9, 21, 22]. However, to our knowledge there are no studies explicitly validating the registration of $\mathrm{CD}$ and UC diagnosis codes. Furthermore, the first biologic treatment for $\mathrm{CD}$ and $\mathrm{UC}$ was infliximab, which was

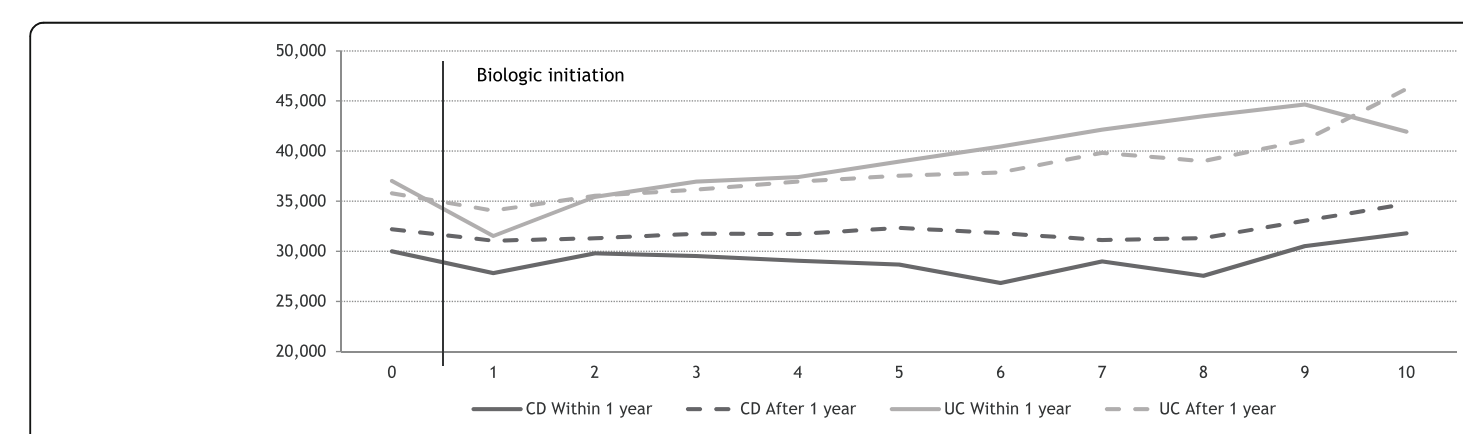

Fig. 4 Average annual individual production value after biologic initiation, stratified on timing of treatment initiation related to diagnosis 
introduced to the European market in 1999, followed by adalimumab in 2003. Our study period was 2003-2016 covering the majority of the period with available biologic treatments, however more patients have initiated biologic treatment in the more recent years. Another potential limitation to this study is that it did not capture quality of life measures, which are important factors when assessing patients' healthcare resource utilization, production values, and in determining the success or failure of a biologic treatment.

Finally, the end of follow up for each case was either due to death or the end of the data period, which was 2016. This study was not able to include information on emigrations meaning cases that emigrated from Denmark at some point during the study period will not have any registered costs after emigration, thus reducing the average cost estimate. Consequently, average costs might have been underestimated.

\section{Conclusions}

$\mathrm{CD}$ and UC patients receiving biologic treatment had higher average annual healthcare costs and lower average annual production values, compared to patients not receiving biologic treatment. For the healthcare costs, the main cost drivers were outpatient visits and admissions. The timing of biologic treatment (early after diagnosis vs. later) does influence the costs, but the cost differences are minor.

\section{Abbreviations}

IBD: Inflammatory bowel diseases; CD: Crohn's disease; UC: Ulcerative colitis; CRS: Danish Civil Registration System; NHSR: National Health Service Register; NPR: National Patient Register; DREAM: Danish Longitudinal Database on Employment; ICD-10: International Classification of Diseases 10th edition; DAGS: Danish outpatient; DRG: Diagnosis Related Group

\section{Acknowledgements}

Not applicable.

\section{Authors' contributions}

$K V, T R J, N Q$ and PM contributed to the concept and design of the study, review and interpretation of the data, drafting and critical review of the manuscript, and approval of the final draft. SA, AB contributed to the review and interpretation of the data, drafting and critical review of the manuscript, and approval of the final draft. $J O$ contributed to the concept and design of the study, data acquisition, extraction and analysis, review and interpretation of the data, drafting and critical review of the manuscript, and approval of the final draft.

\section{Funding}

This work was supported by Janssen Pharmaceuticals. Data collection was carried out by Incentive, with financial support from the funder. The funder also provided support in the form of salaries for authors $\mathrm{KV}, \mathrm{SA}, \mathrm{AB}$.

\section{Availability of data and materials}

The data that support the findings of this study are available from Statistics Denmark's Research Service, but restrictions apply to the availability of these data, which were used under license/authorisation for the current study, and so are not publicly available. Additional data analyses are however available from the authors upon reasonable request and with permission of Statistics Denmark's Research Service.

\section{Declarations}

\section{Ethics approval and consent to participate}

The study was register-based and complied with the regulations and instructions set up by the Danish Data Protection Agency, in which we received the following approval code (J. nr. 2014-54-0664). Danish legislation permits researchers and others with authorisation to access the databases. Ethics committee approval and written informed consent are not required for register-based research according to Danish law. Only anonymized data was used, data is presented in aggregate and anonymous form, and study participants were not contacted nor required any active participation.

\section{Consent for publication}

Not applicable.

\section{Competing interests}

This study was supported by an unrestricted grant from Janssen EMEA. SA, $A B$ and $K V$ are employees at Janssen. TRJ does not have any competing interests to declare. Incentive was a paid vendor by Janssen. JO is an employee at Incentive. NQ and PM acted as scientific experts.

\section{Author details}

${ }^{1} J a n s s e n-C i l a g$, Bregnerødvej 133, 3460 Birkerød, Denmark. ${ }^{2}$ Incentive, Holte, Denmark. ${ }^{3}$ LEO Pharma, Ballerup, Denmark. ${ }^{4}$ Surgical Department A and IBD Care, Odense University Hospital, Odense, Denmark. ${ }^{5}$ Gastroenterology Department, North Zealand University Hospital, Frederikssund, Denmark. 'Janssen-Cilag, High Wycombe, UK.

Received: 11 January 2021 Accepted: 23 July 2021

Published online: 18 August 2021

\section{References}

1. Kaplan GG. The global burden of IBD: from 2015 to 2025. Nat Rev Gastroenterol Hepatol. 2015;12(12):720-7.

2. Hanauer SB. Inflammatory bowel disease: epidemiology, pathogenesis, and therapeutic opportunities. Inflamm Bowel Dis. 2006;12(Suppl 1):S3-9.

3. Lönnfors S, Vermeire S, Greco M, Hommes D, Bell C, Avedano L. IBD and health-related quality of life - discovering the true impact. J Crohns Colitis. 2014;8(10):1281-6.

4. Cohen RD, Yu AP, Wu EQ, Xie J, Mulani PM, Chao J. Systematic review: the costs of ulcerative colitis in Western countries. Aliment Pharmacol Ther. 2010;31(7):693-707.

5. Gay M, Crohn's. Colitis and Employment - from Career Aspirations to Reality. Hertfordshire: Crohn's and Colitis UK; 2011.

6. Statistics Denmark. Register- og variabeloversigter [Register and variables] 2018. Available from: http://www.dst.dk/extranet/forskningvariabellister/ Oversigt\%20over\%20registre.html.

7. Sundhedsdatastyrelsen. Sundhedsregistre - Dokumentation af registre Available from: https://www.esundhed.dk/NewSiteAnnouncement\#P2d44 b52629494859a324fb2f34fd01ee_2_282iT0. [cited 27 Sep 2018].

8. Andersen JS, Olivarius NDF, Krasnik A. The Danish National Health Service Register. Scand J Public Health. 2011;39(7 Suppl):34-7.

9. Schmidt M, Schmidt SAJ, Sandegaard JL, Ehrenstein V, Pedersen L, Sørensen HT. The Danish National Patient Registry: a review of content, data quality, and research potential. Clin Epidemiol. 2015;7:449-90.

10. Lynge E, Sandegaard JL, Rebolj M. The Danish National Patient Register. Scand J Public Health. 2011;39(7):30-3.

11. DREAM databasen dokumentation. Available from: http://www.dst.dk/da/ TilSalg/Forskningsservice/Data/Andre Styrelser. [cited 17 Nov 2017].

12. Vadstrup K, Alulis S, Borsi A, Elkjaer Stallknecht S, Nielsen A, Rikke Jørgensen T, et al. Societal costs attributable to Crohn's disease and ulcerative colitis within the first 5 years after diagnosis: a Danish nationwide cost-of-illness study 2002-2016. Scand J Gastroenterol. 2020;55(1):41-6.

13. Vadstrup K, Alulis S, Borsi A, Gustafsson N, Nielsen A, Wennerström ECM, et al. Cost Burden of Crohn's Disease and Ulcerative Colitis in the 10-Year Period Before Diagnosis_A Danish Register-Based Study From 2003-2015. Inflamm Bowel Dis. 2019; Available from: https://academic. oup.com/ibdjournal/advance-article/doi/10.1093/ibd/izz265/5613986. [cited 27 Dec 2019].

14. Alulis S, Vadstrup K, Borsi A, Nielsen A, Rikke Jørgensen T, Qvist N, et al. Treatment patterns for biologics in ulcerative colitis and Crohn's disease: a 
Danish Nationwide Register Study from 2003 to 2015. Scand J

Gastroenterol. 2020;2:1-7.

15. Statistics Denmark. Statistikbanken, Table SAO01. Available from: http:// www.statistikbanken.dk/10328. [cited 27 Sep 2017].

16. Statistics Denmark. Statistikbanken, Table AKU502. Available from: http:// www.statistikbanken.dk/aku502. [cited 27 Sep 2017].

17. Danish Regions. Økonomisk Vejledning 2017. Available from: http://www. regioner.dk/aftaler-og-oekonomi/oekonomisk-vejledning/oekonomiskvejledning-2017. [cited 7 Oct 2020].

18. Targownik LE, Kaplan GG, Witt J, Bernstein CN, Singh H, Tennakoon A, et al. Longitudinal Trends in the Direct Costs and Health Care

Utilization Ascribable to Inflammatory Bowel Disease in the Biologic Era: Results From a Canadian Population-Based Analysis. Am J Gastroenterol. 2020;115(1):128-37.

19. Brandes A, Groth A, Gottschalk F, Wilke T, Ratsch BA, Orzechowski H-D, et al. Real-world biologic treatment and associated cost in patients with inflammatory bowel disease. Z Gastroenterol. 2019;57(7):843-51.

20. Qvist N, Vadstrup K, Alulis S, Borsi A, Munkholm P, Olsen J. Increased use of biologics in the era of TNF-a inhibitors did not reduce surgical rate but prolonged the time from diagnosis to first time intestinal resection among patients with Crohn's disease and ulcerative colitis - a Danish register-based study from 2003-2016. Scand J Gastroenterol. 2021;56(5):537-44.

21. Thygesen LC, Daasnes C, Thaulow I, Brønnum-Hansen H. Introduction to Danish (nationwide) registers on health and social issues: structure, access, legislation, and archiving. Scand J Public Health. 2011;39(7 Suppl):12-6.

22. Kruse M, Christiansen T. Register-Based Studies of Healthcare Costs. Scand J Public Health. 2011;39:206-9.

\section{Publisher's Note}

Springer Nature remains neutral with regard to jurisdictional claims in published maps and institutional affiliations.

Ready to submit your research? Choose BMC and benefit from:

- fast, convenient online submission

- thorough peer review by experienced researchers in your field

- rapid publication on acceptance

- support for research data, including large and complex data types

- gold Open Access which fosters wider collaboration and increased citations

- maximum visibility for your research: over $100 \mathrm{M}$ website views per year

At $\mathrm{BMC}$, research is always in progress.

Learn more biomedcentral.com/submissions 